\title{
Glutathione Reductase Is Inhibited by Acetaminophen-glutathione Conjugate In Vitro
}

\author{
T. ROUŠAR ${ }^{1,2}$, P. PAŘíK ${ }^{3}$, O. KUČERA ${ }^{1}$, M. BARTOŠ ${ }^{4}$, Z. ČERVINKOVÁ $^{1}$
}

${ }^{1}$ Department of Physiology, Faculty of Medicine in Hradec Králové, Charles University in Prague, Hradec Králové, Czech Republic, ${ }^{2}$ Department of Biological and Biochemical Sciences, Faculty of Chemical Technology, University of Pardubice, Pardubice, Czech Republic, ${ }^{3}$ Institute of Organic Chemistry and Technology, Faculty of Chemical Technology, University of Pardubice, Pardubice, Czech Republic, ${ }^{4}$ Department of Analytical Chemistry, Faculty of Chemical Technology, University of Pardubice, Pardubice, Czech Republic

Received January 13, 2009

Accepted March 17, 2009

On-line June 19, 2009

\section{Summary}

The aim of the present work was to investigate a new mechanism likely contributing to the toxic action of acetaminophen, especially to explore the possible inhibition of glutathione reductase through an acetaminophen-glutathione conjugate (APAP-SG). APAP-SG conjugate was synthesized by organic synthesis and purified by column chromatography. The inhibitory effect of the conjugate on two types of glutathione reductase (from yeasts and rat hepatocytes) was tested spectrophotometrically. We found that the enzyme activity was reduced similarly after the treatment with $2.96 \mathrm{mM}$ acetaminophenglutathione conjugate in both yeast and hepatocyte glutathione reductases (GR); the enzyme activity was inhibited to $52.7 \pm 1.5 \%(2.4 \pm 0.3 \mathrm{mU} / \mathrm{ml})$ in yeast GR (control activity was $5.6 \pm 0.3 \mathrm{mU} / \mathrm{ml})$ and to $48.1 \pm 8.8 \%(2.2 \pm 0.2 \mathrm{mU} / \mathrm{ml})$ in rat hepatocytes lysate GR (control activity was $5.2 \pm 0.2 \mathrm{mU} / \mathrm{ml}$ ). In addition, the enzyme activity (from hepatocytes lysate) was decreased to $79 \pm 7 \%, 67 \pm 2 \%$ and $39 \pm 7 \%$, in $0.37,1.48$ and $3.7 \mathrm{mM}$ concentration of the conjugate, respectively. We found that glutathione reductase, the essential enzyme of the antioxidant system, was dose-dependently inhibited by the product of acetaminophen metabolism - the conjugate of acetaminophen and glutathione.

\section{Key words}

Acetaminophen toxicity • Glutathione reductase • Glutathione • Hepatotoxicity

\section{Corresponding author}

T. Roušar, Department of Physiology, Faculty of Medicine in Hradec Králové, Charles University in Prague, Šimkova 870, 50038 Hradec Králové, Czech Republic. Fax: (+420) 495518772. E-mail: Tomas.Rousar@upce.cz

\section{Introduction}

Acetaminophen (APAP) is at present one of the mostly used analgesics and antipyretics. It is considered to be a safe drug when used at therapeutic doses. On the other hand, the acetaminophen overdosing is the most frequent cause of acute liver failure in men (Lee 2004). Hence, the mechanisms of acetaminophen toxicity have been studied very intensively recently.

At therapeutic doses, acetaminophen is detoxified by three major pathways in the liver. The most of APAP dose is conjugated with glucuronate and sulfate (about $80 \%$ and $10 \%$, respectively). Remaining part of APAP is oxidized by cytochrome P450 to a toxic metabolite, N-acetyl-p-benzoquinone imine (NAPQI). This compound is detoxified by either spontaneous or enzyme-catalyzed reaction with glutathione (GSH) resulting in a conjugate APAP-SG, 3-(glutathion-S-yl) acetaminophen. In APAP overdose, the glucuronidation and sulfation pathways are saturated, acetaminophen is being oxidized to NAPQI in much higher extent and GSH stores become depleted. Consequently, NAPQI binds to 
various proteins, the APAP-protein adducts are produced, and due to GSH depletion, there is an increase of oxidative stress in the cell (Jollow et al. 1973). These actions result in hepatocellular death seen as centrilobular necrosis in the liver (Mitchell et al. 1973, Jaeschke and Bajt 2006).

So far, numerous mechanisms contributing to the hepatocyte injury have been found. Except of GSH depletion and reactive oxygen species (ROS) production, the lipoperoxidation, mitochondrial permeability transition pore opening (Kon et al. 2004) and impairment of mitochondrial respiration have also been mentioned. Despite the processes cited above, the crucial causative mechanism of the toxicity remains unknown (Kaplowitz 2004, Jaeschke and Bajt 2006). Two possible theories have been postulated so far - the oxidative and the metabolic one. The oxidative theory proposes the explanation of the damage by an increase of oxidative stress, the latter one by binding of NAPQI to SH-groups of proteins supposing their function to be impaired (James et al. 2003). Unfortunately, neither the oxidative nor the metabolic theory explain the entire toxicity found in acetaminophen-treated liver cells at all points.

As we have recently described (Roušar et al. 2009), acetaminophen toxicity is linked to reduced activity of glutathione reductase (GR) in vitro. It is a crucial enzyme in glutathione metabolism because it reduces glutathione disulphide (GSSG) back to the reduced form, GSH. Thus, this enzyme is essentially important during oxidative stress, where the level of GSSG increases and the inhibition of glutathione reductase could be a principal mechanism in acetaminophen toxicity. Since the cause of the enzyme inhibition remains unknown, the aim of our work was focused on an attempt to find and describe the reason of decreased activity of glutathione reductase (using two different types of glutathione reductases, i.e. from yeast and from rat hepatocytes). In addition, we wanted to prove the hypothesis that APAP-SG conjugate may play an important role in the mechanism of APAP toxicity. The experiments were carried out in vitro. The outcomes were aimed to serve as the preliminary data for following testing in cells and in vivo.

\section{Materials and Methods}

\section{Chemicals}

Glutathione reductase (from Saccharomyces cerevisiae; $160 \mathrm{U} / \mathrm{mg}$ prot.), GSH, glutathione disulphide, sodium phosphate buffer, potassium phosphate buffer, hydrochloric acid, acetaminophen and NADPH were purchased from Sigma-Aldrich (USA). The reagents used to the synthesis and purification of APAP-SG conjugate were purchased from Lachema (Czech Republic).

\section{Preparation of acetaminophen-glutathione conjugate}

The APAP-SG conjugate was synthesized according to the method of Thatcher and Murray (2001), the separation of the conjugate was performed as a modification of the method described by Allameh and Alikhani (2002). Briefly, sodium hydroxide solution (8 g in $250 \mathrm{ml}$ of distilled water) was added to the solution of silver nitrate ( $4.224 \mathrm{~g}$ in $65 \mathrm{ml}$ of distilled water) and the precipitated silver oxide was filtered off using glass sinter and washed.

Acetaminophen (0.428 g) was suspended in $100 \mathrm{ml}$ of dry chloroform and just prepared silver oxide $(2.2 \mathrm{~g})$ was added. The suspension was stirred, filtered and the NAPQI solution was obtained. Glutathione $(0.857 \mathrm{~g})$ was dissolved in $250 \mathrm{ml}$ of $0.1 \mathrm{M}$ sodium phosphate buffer pH 7.4 and freshly prepared NAPQI solution was added drop wise. Reaction mixture was separated and the water was evaporated at $40{ }^{\circ} \mathrm{C}$. Residue of the mixture was stirred in methanol for $3 \mathrm{~h}$ and filtered. Methanol was evaporated using vacuum evaporator.

APAP-SG conjugate was separated using column chromatography on Silicagel 60 (Merck, Germany) where the separation of the reaction residue containing APAP, APAP-SG and GSSG was performed; mobile phase consisted of methanol/water (9:1). The fractions $(10 \mathrm{ml})$ were collected after separation and analyzed by thin layer chromatography (TLC) according to Allameh and Alikhani (2002). The detection was carried out using TLC on Silicagel 60 F254 (Merck, Germany) with methanol/water (9:1) as a mobile phase; bands were visualized by $\lambda=254 \mathrm{~nm}$ (APAP, APAP-SG) or after reaction with $0.2 \%$ ninhydrin (APAP-SG, GSSG). The Rf values for APAP, APAP-SG and GSSG were approximatelly $0.9,0.7$ and 0.3 , respectively. The Rf values of GSSG and APAP were determined after comparison with standard values. APAP-SG conjugate was obtained as a solid by desiccation of the fractions with proved APAP-SG only.

\section{Preparation of hepatocyte lysates}

Hepatocytes were isolated from male albino Wistar rats (250-280 g; Biotest, Czech Republic) by 
collagenase perfusion (Berry et al. 1991). The viability of freshly isolated hepatocytes was more than $90 \%$ as confirmed by trypan blue exclusion. Isolated hepatocytes were suspended in Williams' E medium and diluted to final density of $10^{6}$ cells per $\mathrm{ml}$. The cells were sonicated (Bandelin Sonopuls sonicator, Germany) and the lysates were centrifuged $\left(4^{\circ} \mathrm{C}, 10 \mathrm{~min}, 10000 \mathrm{~g}\right)$. The inhibition of glutathione reductase was tested in supernatant which was diluted in distilled water to gain the final GR activity similar to samples containing yeast glutathione reductase. The specific activity of rat hepatocytes lysate GR was $22 \mathrm{mU} / \mathrm{mg}$ prot.

All animals received care according to the guidelines set by the Institutional Animal Use and Care Committee of the Charles University, Prague, Czech Republic.

\section{GR activity assay}

The principle of the method is the reduction of oxidized glutathione by glutathione reductase in the presence of NADPH (Carlberg and Mannervik 1975). Activity of both yeast (from Saccharomyces cerevisiae; $160 \mathrm{U} / \mathrm{mg}$ prot.) and hepatocytes lysate GR was determined at $25^{\circ} \mathrm{C}$ in $0.2 \mathrm{M}$ potassium phosphate buffer ( $\mathrm{pH} 7.5$ ) by monitoring of NADPH absorbance decline $(\lambda=340 \quad \mathrm{~nm})$ using well-plate spectrophotometer INFINITE M200 (Tecan, Austria). The volumes of solutions were $50 \mu \mathrm{l} \mathrm{GR,} 25 \mu \mathrm{l} \mathrm{GSSG}(3.7 \mathrm{mM})$ and the assay was started by addition of $50 \mu \mathrm{NADPH}(0.7 \mathrm{mM})$; the values in the brackets mean the final concentrations of a compound in a well. The decline of absorbance was monitored during $20 \mathrm{~min}$ and the results were presented as a dependence of absorbance on time. One Unit was defined as an amount of the enzyme which will reduce $1 \mu$ mole of oxidized glutathione per minute at $\mathrm{pH} 7.6$ at $25{ }^{\circ} \mathrm{C}$, using a molar extinction coefficient of $6.22 \times 10^{3}$ for NADPH.

\section{Estimation of GR inhibition by APAP-SG conjugate}

The inhibition of both yeast and rat hepatocytes lysate GR activities by APAP-SG conjugate were assayed in well plates. The stock solution of APAP-SG (100 mM) was prepared. Then, the solutions with various concentrations of APAP-SG $(5 \mathrm{mM}, 10 \mathrm{mM}, 20 \mathrm{mM}$, $40 \mathrm{mM}, 50 \mathrm{mM}$ ) were prepared by dilution in distilled water. $10 \mu \mathrm{l}$ of each solution were added to the mixture of GR $(50 \mu \mathrm{l})$ and GSSG $(25 \mu \mathrm{l})$ to assess the inhibitory effect. The measurement was started by the addition of NADPH $(50 \mu \mathrm{l})$ and monitored by $\lambda=340 \mathrm{~nm}$ spectrophotometrically for $20 \mathrm{~min}$ at $25{ }^{\circ} \mathrm{C}$. Control samples were prepared by identical protocol, the distilled water $(10 \mu \mathrm{l})$ was added instead of APAP-SG conjugate.

\section{Statistical analysis}

All experiments were repeated at least two times with negligible differences among results. The results were processed by one-way ANOVA test, followed by Bonferroni post-hoc test. The results are expressed as the mean \pm S.D. (GraphPad Prism 4.03 for Windows, GraphPad Software, USA). $\mathrm{p}<0.05$ was considered as significant.

\section{Results}

Purified APAP-SG conjugate was used to estimation of possible inhibitory effect in two types of glutathione reductase from yeast or rat hepatocyte lysate. The results show (Fig. 1) that the activity of both types of GR was decreased similarly in comparison to control in the presence of $2.96 \mathrm{mM}$ APAP-SG. The enzyme activity was inhibited to $52.7 \pm 1.5 \%(2.4 \pm 0.3 \mathrm{mU} / \mathrm{ml})$ in yeast GR (control activity $5.6 \pm 0.3 \mathrm{mU} / \mathrm{ml}$ ) and to $48.1 \pm 8.8 \%$ $(2.2 \pm 0.2 \mathrm{mU} / \mathrm{ml})$ in rat hepatocyte lysate GR (control activity was $5.2 \pm 0.2 \mathrm{mU} / \mathrm{ml}$ ). Based on these results, all other experiments were performed using rat liver GR.

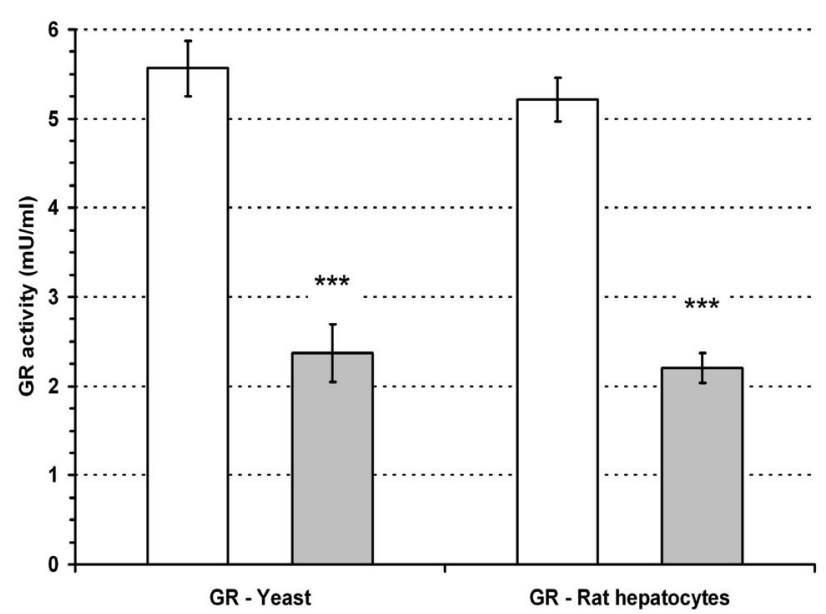

Fig. 1. Comparison of inhibitory effect of acetaminophenglutathione conjugate, APAP-SG $(2.96 \mathrm{mM})$ on glutathione reductases from yeast and rat hepatocyte lysate. Glutathione reductases from yeast and rat hepatocyte were treated with a solution consisting of $2.96 \mathrm{mM}$ APAP-SG conjugate (gray columns) and the decrease in absorbance $(\lambda=340 \mathrm{~nm})$ was measured after addition of NADPH for 20 minutes. The results were evaluated and compared to control (white columns) which consisted of the same concentrations of all compounds, excluding APAP-SG conjugate. Results are expressed as mean \pm S.D. ( $\mathrm{n}=4 ; * * *, \mathrm{p}<0.001$, compared to control). 


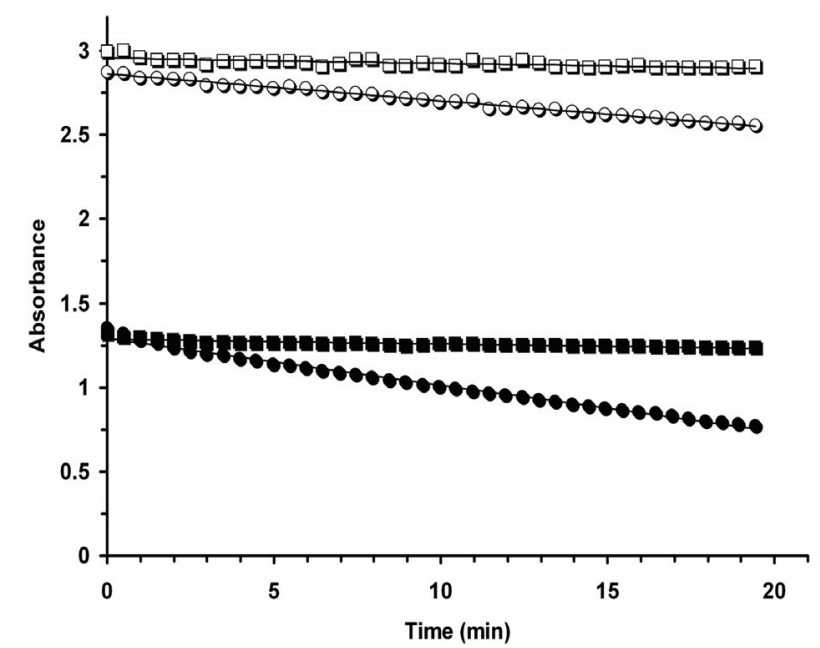

Fig. 2. Time course of the inhibition of glutathione reductase (from rat hepatocytes lysate) by acetaminophen-glutathione conjugate, APAP-SG $(2.96 \mathrm{mM})$. Glutathione reductase $(8 \mathrm{mU} / \mathrm{ml})$ was treated with $2.96 \mathrm{mM}$ APAP-SG conjugate (o, open circles) and the decrease in absorbance of NADPH $(\lambda=340 \mathrm{~nm})$ was measured. After $20 \mathrm{~min}$, the results were evaluated and compared to control $(\bullet$, closed circles) which consisted of the same concentrations of compounds, excluding APAP-SG conjugate. The blank samples without glutathione disulfide were also assessed - in the presence of the APAP-SG conjugate ( $\square$, open squares) and without APAP-SG conjugate $(\boldsymbol{\square}$, closed squares).

We analyzed also blank samples in all experiments. The blank samples did not contain GSSG and the obtained absorbance signals were subtracted in both control and APAP-SG-treated samples. The results show that the blank signal accounts for only $2 \%$ and $4 \%$ of absorbance decrease in control and APAP-SG-treated samples, respectively (Fig. 2). Although we did not purified the hepatocyte GR, the values of blank signals showed, that our conditions of GR assay were rather specific.

The inhibitory effect on hepatocyte glutathione reductase was tested in a number of APAP-SG concentrations. We found that the enzyme activity was decreased proportionally to increasing APAP-SG concentration (Fig. 3). The GR activity was inhibited to $79.8 \pm 7.0 \%, 72.1 \pm 0.5 \%, 66.9 \pm 2.2 \%, 48.0 \pm 7.1 \%$ and $39.5 \pm 7.4 \%$ in presence of $0.37 \mathrm{mM}, 0.74 \mathrm{mM}, 1.48 \mathrm{mM}$, $2.96 \mathrm{mM}$ and $3.7 \mathrm{mM}$ APAP-SG, respectively. GR activity in controls was $8.7 \pm 0.5 \mathrm{mU} / \mathrm{ml}$.

\section{Discussion}

Acetaminophen toxicity is a complex process where many mechanisms contribute to the hepatocyte impairment. Since the acetaminophen overdosing is one of the mostly found causes of acute liver failure (Lee

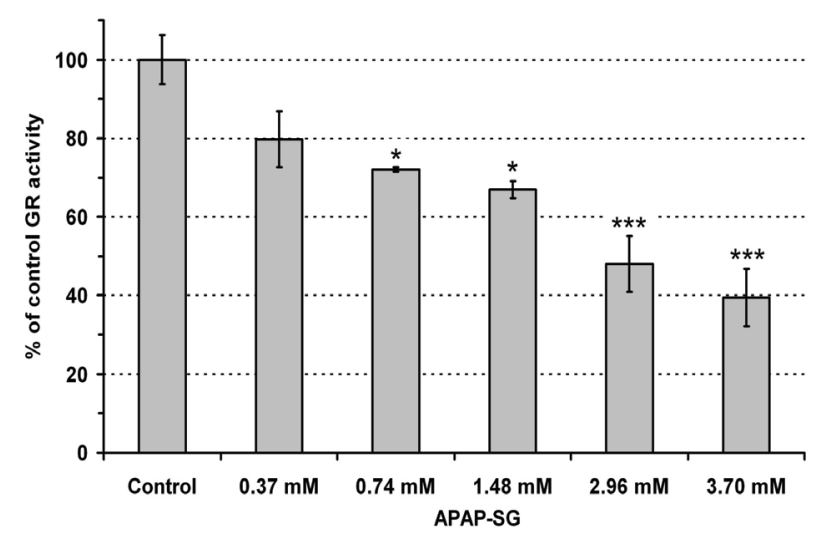

Fig. 3. Inhibition of glutathione reductase (from rat hepatocyte lysate) by acetaminophen-glutathione conjugate (APAP-SG). Ratio of resultant glutathione reductase activities to control signal $(8.7 \pm 0.5 \mathrm{mU} / \mathrm{ml})$ in samples treated with various concentrations of APAP-SG conjugate $(0.37 \mathrm{mM}, 0.74 \mathrm{mM}, 1.48 \mathrm{mM}, 2.96 \mathrm{mM}$ and $3.70 \mathrm{mM})$. The absorbance decrease of $\operatorname{NADPH}(\lambda=340 \mathrm{~nm})$ was monitored for 20 min. Results are expressed as mean \pm S.D. ( $\mathrm{n}=2-4 ; *, \mathrm{p}<0.05, * * *, \mathrm{p}<0.001$, compared to control).

2004), the estimation of APAP toxicity has been extensively studied.

Recently, a number of reviews and original papers have been published in which new mechanisms contributing to the liver damage have been described. However, none of the mechanisms explain the cause of the hepatocyte damage completely (James et al. 2003, Jaeschke and Bajt 2006).

The former assumption explaining a cause of APAP toxicity is a metabolic one. It is linked to increased NAPQI production during metabolic phase in the APAP overdose. After GSH stores are depleted, NAPQI binds to various proteins and the APAP-adducts are produced (Jollow et al. 1973, Qiu et al. 1998). This was believed to impair the protein function. However, none or only a modest change in their activity was found (Pumford et al. 1997).

The oxidative theory proposed that depletion of GSH is followed by enhanced oxidative stress in a short period of time which leads to the hepatocyte injury. Indeed, it was supported by increased lipoperoxidation, ROS production or increased synthesis of nitric oxide (NO) (Hinson et al. 1998, Knight et al. 2001, Jaeschke et al. 2003). However, it is questioned if the oxidative stress is a cause or just a consequence to decreased glutathione levels. It was shown that the increased ROS production follows the GSH depletion (Bajt et al. 2004). Another issue was to determine the localization of ROS production. The role of Kupffer cells, increased NO production or mitochondria as a source of ROS were investigated, but the question concerning the role of ROS 
as the main cause of cell death has not been answered yet (James et al. 2003, Jaeschke and Bajt 2006).

The present work is directed to assess a newly proposed principle contributing to the acetaminophen toxicity. We observed recently that the glutathione reductase activity was reduced in rat hepatocytes treated with acetaminophen (Roušar et al. 2009). This inhibition was proved to be dose-dependent. We ascribed the cause of GR inhibition to the impairment of the enzyme by ROS or toxic aldehydes, as described in several other papers (Ochi 1990, Vessey and Lee 1993). Despite this, we have proposed another theory of the cause of GR inhibition. We have hypothesized that the inhibition could be caused by direct effect of APAP-SG, the conjugate of glutathione and acetaminophen (or NAPQI more precisely).

To prove our hypothesis, we decided to prepare APAP-SG conjugate by organic synthesis. We tested two types of glutathione reductase - a commercially available GR from yeast Saccharomyces cerevisiae and GR from rat hepatocyte lysate. In accordance to our hypothesis, we repeatedly found that APAP-SG inhibits largely yeast and hepatocyte lysate GR; $2.96 \mathrm{mM}$ APAP-SG was able to inhibit glutathione reductase activity by about $50 \%$.

The assessed concentrations of APAP-SG (0.37 $3.7 \mathrm{mM}$ ) may be comparable to the APAP-SG levels occurring in hepatocytes. In APAP overdose, the levels of APAP in the cells are in milimolar range (Mitchell et al. 1973); the GSH levels in hepatocytes were found in milimolar range as well (Pastore et al. 2003). After the glucuronidation and sulfation pathways are saturated, the most of the dose is oxidized to NAPQI. Thus, the described effect of APAP-SG on GR activity is likely to occur in the cells. The possibly substantial role of GR in the acetaminophen toxicity is supported by the work of Armesto et al. (1993) who demonstrated that a drug, lobenzarit, enhances GR activity in mice. Since lobenzarit was proved to have hepatoprotective properties in APAP overdose, this effect may be caused just by decreasing of the GR inhibition present in APAP-treated hepatocytes.

We propose that the cause of observed GR inhibition by APAP-SG might be due to similar principle as in the case of inhibition of glutathione reductase by S-nitrosoglutathione (Becker et al. 1995). The authors presented that S-nitrosoglutathione was capable of inhibiting the glutathione reductase activity by reversible and/or irreversible mechanism. It follows that GR is able to react with a compound of chemical structure related at least to a half of glutathione disulphide molecule.

The exploration of glutathione reductase inhibition by APAP-SG partially changes the view to acetaminophen toxicity. Indeed, the conjugate of acetaminophen (or more precisely NAPQI) and glutathione always occurs when NAPQI has been formed by cytochrome P450. Moreover, NAPQI production is even catalyzed by glutathione-S-transferase (GST) (Coles et al. 1988). The conjugation of APAP and GSH has been considered till now as a protective mechanism which protects the hepatocyte against the binding of NAPQI to various proteins. The conjugate is consequently transported out of the cell to the bile by MRP-2 (multidrug resistance-associated protein-2) localized in canalicular membrane of hepatocyte (Chen et al. 2003).

Despite generally accepted mechanisms described above, several original works brought results that were not anticipated before. In 2000, the work of Henderson et al. (2000) described the estimation of APAP toxicity in GSTpi knockout mice. GST-pi is an isoenzyme of glutathioneS-transferase which is proved to catalyze the formation of APAP-SG conjugate in the liver (Coles et al. 1988, Henderson and Wolf 2005). Remarkably, the results showed that GST-pi knockout mice were much more resistant to APAP toxicity than wild-type mice. The explanation of that phenomenon was attributed to GSTcatalyzed redox cycling and enhancement of oxidative stress, or to the role of GST-pi as an inhibitor of the stress inducible Jun N-terminal kinase (Henderson et al. 2000). However, the results may be explained convincingly regarding the finding published in this paper.

The hepatocytes from mice lacking GST-pi produce certainly much lower amount of APAP-SG conjugate (Coles et al. 1988). Hence, lower concentration of APAP-SG can lead to a slighter inhibition of GR. Indeed, this is supported by different recoveries of glutathione when comparing wild-type and GST-pi knockout mice treated with acetaminophen (Henderson et al. 2000). These results show that GSH concentrations were decreased in both strains, although GSH levels remained higher at all time points in knockout mice compared to wild-type ones. In addition, the GSH levels almost recovered to pretreatment levels within $5 \mathrm{~h}$ in GSTpi null mice, whereas GSH remained depleted in wild-type mice. The authors tested the protein levels of glutathione biosynthetic enzymes, $\gamma$-glutamylcysteine synthetase and glutathione synthetase, which were essentially unchanged. Hence, the GSH recovery cannot be explained in this way and it is likely that the diverse GSH recovery between mice strains could be influenced by different GR activity.

Another paper was concerned in testing of 
susceptibility of transport-deficient hyperbilirubinemic, MRP-2 deficient rats to acetaminophen (Silva et al. 2005). The treatment of MRP-2 deficient rats with acetaminophen resulted in a finding that mutant rats were more resistant than wild-type rats. The published explanation was that increased expression of certain cytochrome P-450 isoenzymes produced even more NAPQI which caused even larger impairment. On the other hand, the MRP-2 deficiency in rats likely evoked an accumulation of APAP-SG in the hepatocytes leading to the subsequent enhancement of the GR inhibition (Silva et al. 2005). Obviously, an attribute of enhanced NAPQI formation is also important, but the increased toxicity may be again due to increased production of APAP-SG.

For further support of our hypothesis, we sought to find another mechanism capable to enhance APAP-SG intracellular levels. Rzucidlo et al. (2000) published a paper focused on the estimation of acute APAP toxicity in transgenic mice with elevated hepatic glutathione. They hypothesized that due to overexpression of glutathione synthetase and elevated GSH levels, the transgenic mice should be better protected against APAP toxicity. Surprisingly, the expectations were not fulfilled because transgenic mice showed significantly higher level of hepatotoxicity. The cause of this surprising finding was not fully explained. However, regarding our results presented here, the mechanism of higher hepatotoxicity level in mice with elevated glutathione could be easily explained by increased formation of APAP-SG conjugate and augmented inhibition of glutathione reductase.

\section{Conclusions}

The obtained results confirmed our hypothesis that glutathione reductase could be inhibited by APAP-SG conjugate in vitro which is supported by published results of the other authors. Generally, depletion of GSH due to reaction with NAPQI in acetaminophen overdose is always related to acetaminophen toxicity. Since glutathione reductase is a crucial enzyme in maintenance of intracellular GSH levels, the decrease of GR activity raises hepatocyte impairment. In addition, it is generally accepted that the GSH exhaustion results in a number of consequent pathological processes (e.g. ROS production, peroxynitrite formation and/or lipoperoxidation) which lead to GSSG production and to the cell death. Hence, our results shed light on a mechanism that could contribute to the acetaminophen toxicity in the liver.

\section{Conflict of Interest}

There is no conflict of interest.

\section{Acknowledgements}

This work was supported by grants of Ministry of Education, Youth and Sport of the Czech Republic (MSM0021627502, MSM0021620820) and Charles University Grant Agency (GAUK 90/2006). Great thanks belong to O. Štarman for support.

\begin{abstract}
Abbreviations
APAP, acetaminophen; APAP-SG, acetaminophenglutathione conjugate; GR, glutathione reductase; GSH, glutathione (reduced form); GSSG, glutathione disulphide; GST, glutathione-S-transferase; MRP-2, multidrug resistance-associated protein-2; NAPQI, $\mathrm{N}$-acetyl-p-benzoquinone imine; ROS, reactive oxygen species; TLC, thin layer chromatography.
\end{abstract}

\section{References}

ALLAMEH A, ALIKHANI N: Acetaminophen-glutathione conjugate formation in a coupled cytochrome P-450glutathione S-transferase assay system mediated by subcellular preparations from adult and weanling rat tissues. Toxicol In Vitro 16: 637-641, 2002.

ARMESTO J, FRUTOS N, GONZALEZ R, PASCUAL C: In vitro activation of hepatic glutathione reductase from mice by lobenzarit disodium. Agents Actions 39: 69-71, 1993.

BAJT ML, KNIGHT TR, LEMASTERS JJ, JAESCHKE H: Acetaminophen-induced oxidant stress and cell injury in cultured mouse hepatocytes: protection by N-acetyl cysteine. Toxicol Sci 80: 343-349, 2004.

BECKER K, GUI M, SCHIRMER RH: Inhibition of human glutathione reductase by S-nitrosoglutathione. Eur J Biochem 234: 472-478, 1995.

BERRY M, EDWARDS A, BARRITT G: High-yield preparation of isolated hepatocytes from rat liver. In: Isolated Hepatocytes Preparation, Properties and Application. R. BURDON, P. VAN KNIPPENBERG (eds), Elsevier, New York, 1991, pp 15-81. 
CARLBERG I, MANNERVIK B: Purification and characterization of the flavoenzyme glutathione reductase from rat liver. J Biol Chem 250: 5475-5480, 1975.

COLES B, WILSON I, WARDMAN P, HINSON JA, NELSON SD, KETTERER B: The spontaneous and enzymatic reaction of N-acetyl-p-benzoquinonimine with glutathione: a stopped-flow kinetic study. Arch Biochem Biophys 264: 253-260, 1988.

HENDERSON CJ, WOLF CR: Disruption of the glutathione transferase pi class genes. Methods Enzymol 401: 116-135, 2005.

HENDERSON CJ, WOLF CR, KITTERINGHAM N, POWELL H, OTTO D, PARK BK: Increased resistance to acetaminophen hepatotoxicity in mice lacking glutathione S-transferase Pi. Proc Natl Acad Sci USA 97: 12741-12745, 2000.

HINSON JA, PIKE SL, PUMFORD NR, MAYEUX PR: Nitrotyrosine-protein adducts in hepatic centrilobular areas following toxic doses of acetaminophen in mice. Chem Res Toxicol 11: 604-607, 1998.

CHEN C, HENNIG GE, MANAUTOU JE: Hepatobiliary excretion of acetaminophen glutathione conjugate and its derivatives in transport-deficient (TR-) hyperbilirubinemic rats. Drug Metab Dispos 31: 798-804, 2003.

JAESCHKE H, BAJT ML: Intracellular signaling mechanisms of acetaminophen-induced liver cell death. Toxicol Sci 89: 31-41, 2006.

JAESCHKE H, KNIGHT TR, BAJT ML: The role of oxidant stress and reactive nitrogen species in acetaminophen hepatotoxicity. Toxicol Lett 144: 279-288, 2003.

JAMES LP, MAYEUX PR, HINSON JA: Acetaminophen-induced hepatotoxicity. Drug Metab Dispos 31: 1499-1506, 2003.

JOLLOW DJ, MITCHELL JR, POTTER WZ, DAVIS DC, GILLETTE JR, BRODIE BB: Acetaminophen-induced hepatic necrosis. II. Role of covalent binding in vivo. J Pharmacol Exp Ther 187: 195-202, 1973.

KAPLOWITZ N: Acetaminophen hepatoxicity: what do we know, what don't we know, and what do we do next? Hepatology 40: 23-26, 2004.

KNIGHT TR, KURTZ A, BAJT ML, HINSON JA, JAESCHKE H: Vascular and hepatocellular peroxynitrite formation during acetaminophen toxicity: role of mitochondrial oxidant stress. Toxicol Sci 62: 212-220, 2001.

KON K, KIM JS, JAESCHKE H, LEMASTERS JJ: Mitochondrial permeability transition in acetaminophen-induced necrosis and apoptosis of cultured mouse hepatocytes. Hepatology 40: 1170-1179, 2004.

LEE WM: Acetaminophen and the U.S. Acute Liver Failure Study Group: lowering the risks of hepatic failure. Hepatology 40: 6-9, 2004.

MITCHELL JR, JOLLOW DJ, POTTER WZ, DAVIS DC, GILLETTE JR, BRODIE BB: Acetaminophen-induced hepatic necrosis. I. Role of drug metabolism. J Pharmacol Exp Ther 187: 185-194, 1973.

OCHI T: Effects of an organic hydroperoxide on the activity of antioxidant enzymes in cultured mammalian cells. Toxicology 61: 229-239, 1990.

PASTORE A, FEDERICI G, BERTINI E, PIEMONTE F: Analysis of glutathione: implication in redox and detoxification. Clin Chim Acta 333: 19-39, 2003.

PUMFORD NR, HALMES NC, MARTIN BM, COOK RJ, WAGNER C, HINSON JA: Covalent binding of acetaminophen to N-10-formyltetrahydrofolate dehydrogenase in mice. J Pharmacol Exp Ther 280: 501-505, 1997.

QIU Y, BENET LZ, BURLINGAME AL: Identification of the hepatic protein targets of reactive metabolites of acetaminophen in vivo in mice using two-dimensional gel electrophoresis and mass spectrometry. $J$ Biol Chem 273: 17940-17953, 1998.

ROUŠAR T, KUČERA O, KŘIVÁKOVÁ P, LOTKOVÁ H, KANĎÁR R, MUŽÁKOVÁ V, ČERVINKOVÁ Z: Evaluation of oxidative status in acetaminophen treated rat hepatocytes in culture. Physiol Res 58: 239-246, 2009.

RZUCIDLO SJ, BOUNOUS DI, JONES DP, BRACKETT BG: Acute acetaminophen toxicity in transgenic mice with elevated hepatic glutathione. Vet Hum Toxicol 42: 146-150, 2000.

SILVA VM, THIBODEAU MS, CHEN C, MANAUTOU JE: Transport deficient (TR-) hyperbilirubinemic rats are resistant to acetaminophen hepatotoxicity. Biochem Pharmacol 70: 1832-1839, 2005. 
THATCHER NJ, MURRAY S: Analysis of the glutathione conjugate of paracetamol in human liver microsomal fraction by liquid chromatography mass spectrometry. Biomed Chromatogr 15: 374-378, 2001.

VESSEY DA, LEE KH: Inactivation of enzymes of the glutathione antioxidant system by treatment of cultured human keratinocytes with peroxides. J Invest Dermatol 100: 829-833, 1993. 